\title{
Optimal Diet Strategies for Weight Loss and Weight Loss Maintenance
}

\author{
Ju Young Kim* \\ Department of Family Medicine, Seoul National University Bundang Hospital, Seongnam, Korea
}

Obesity has become one of the most important public health problems worldwide, which suggests the need for evidence-based dietary strategies for weight loss and its maintenance. Weight management depends upon complex factors such as amount of food eaten, type of food eaten, and timing of meals. In this review, we identified evidence-based dietary strategies for weight management based on these three components. An energy deficit is the most important factor in weight loss. A low-calorie diet with a low fat or carbohydrate content has been recommended; however, in some cases, a very-low-calorie diet is required for a short period. Some macronutrient composition-based diets, such as the ketogenic diet or high-protein diet, could be considered in some cases, although the potential risks and long-term effectiveness remain unknown. Meal timing is also an important factor in weight management, and higher-calorie breakfasts in combination with overnight fasting may help to prevent obesity. Our review indicated that there is no single best strategy for weight management. Hence, strategies for weight loss and its maintenance should be individualized, and healthcare providers must choose the best strategy based on patient preferences.

Key words: Carbohydrate-restricted diet, Fat-restricted diet, High-protein diet, Mediterranean diet, Fasting

\author{
Received June 25, 2020 \\ Reviewed July 14, 2020 \\ Accepted August 19, 2020 \\ *Corresponding author \\ Ju Young Kim \\ (iD) \\ https://orcid.org/0000-0001-6018-3337 \\ Department of Family Medicine, Seoul \\ National University Bundang Hospital, \\ 82 Gumi-ro 173beon-gil, Bundang-gu, \\ Seongnam 13620, Korea \\ Tel: +82-31-787-7796 \\ Fax: +82-31-787-4014 \\ E-mail:kkamduri@snubh.org
}

\section{INTRODUCTION}

More than 650 million adults worldwide suffer from obesity, and the prevalence of this condition has increased rapidly during the past 50 years. ${ }^{1}$ Obesity has become one of the most important public health problems globally and is strongly associated with type 2 diabetes mellitus (T2DM); cardiovascular diseases including myocardial infarction and stroke; osteoarthritis; obstructive sleep apnea; depression; and some types of cancer, such as breast, ovarian, prostate, liver, kidney, and colon cancer. ${ }^{2,3}$

Optimal diets for weight management have been a topic of debate not only among researchers, nutrition experts, and healthcare professionals, but also among the general public. ${ }^{4,5}$ According to a meta-analysis of several diet programs, calorie restriction was the primary driver of weight loss, followed by macronutrient composi- tion. ${ }^{6}$ Another study examined the effects of popular diets without specific calorie targets and showed that the Atkins diet resulted in clinically meaningful weight loss after 6 months. ${ }^{7}$ In contrast, another review revealed that the Atkins, Weight Watchers, and Zone diets resulted in modest and similar long-term weight loss after 1 year. ${ }^{8}$ Recently, intermittent fasting and time-restricted eating have become popular and seem to be effective for weight loss. ${ }^{9}$ However, several questions remain unanswered. Does a high-protein diet aid in weight loss and maintenance? Can a ketogenic diet burn fat? Do carbohydrates increase abdominal fat? Can intermittent fasting help one lose weight? New dietary information has only added to the current confusion due to several controversial dietary regimens, and there is no clear guidance on the optimal diet for weight loss.

Obesogenic environments and biological and psychological fac-

Copyright (C) 2021 Korean Society for the Study of Obesity

(a) This is an Open Access article distributed under the terms of the Creative Commons Attribution Non-Commercial License (https://creativecommons.org/licenses/by-nc/4.o/) which permits unrestricted non-commercial use, distribution, and reproduction in any medium, provided the original work is properly cited 
tors all contribute to obesity. ${ }^{10}$ However, obesogenic environments, including social determinants, cultures, and food supply systems, are challenging to modify. Therefore, dietary interventions remain the cornerstone of weight-management strategies, and pharmacologic and surgical interventions also aim to improve dietary management.

Complex factors shape and influence diets, especially for weight management. However, amount of food eaten, type of food consumed (macronutrient composition), and meal timing of meals are the key components of weight-management strategies. In this review, we discuss several evidence-based dietary interventions for weight loss and weight-loss management based on these components.

\section{AMOUNT OF FOOD INTAKE}

\section{Low-calorie diet vs. very-low-calorie diet}

The key component of diets for weight loss and weight-loss maintenance is an energy deficit. Under the "calories-in, caloriesout" model, dietary management has focused on the concept of "eat less, move more," and patients have been advised to consider and calculate their calorie balance whenever they eat. However, energy intake and energy expenditure are dynamic processes influenced by body weight and influence each other. ${ }^{11}$ Thus, interventions aimed at creating an energy deficit through the diet are countered by physiological adaptations that resist weight loss.

A low-calorie diet involves consumption of 1,000-1,500 calories per day; deficits of 500-750 calories per day have been used for weight loss and are recommended by many obesity societies and guidelines. ${ }^{12-15}$ Low-calorie diets typically restrict fats or carbohydrates, neither of which has been determined to be more important for weight loss if only a calorie deficit occurs. The 2018 the Diet Intervention Examining The Factors Interacting with Treatment Success (DIETFITS) study found no significant differences in weight loss between low-fat and low-carbohydrate diets. ${ }^{16}$ However, meal planning and preparation take effort, and weight-loss maintenance requires a sustained low-calorie diet. Moreover, metabolic adaptations to decrease energy expenditure can lead to a plateau with this type of diet, which individuals may misinterpret as "failure" due to "lack of willpower."
Traditionally, a very-low-calorie diet (VLCD), which provides $<800 \mathrm{kcal}$ a day, is not recommended for routine weight management and should only be used in limited circumstances along with medical monitoring according to obesity guidelines. ${ }^{12}$ However, a recent review suggested that a VLCD used in combination with behavioral programs can provide greater long-term weight loss than behavioral programs alone, and that it is tolerable and has few adverse effects. ${ }^{17}$ Additionally, a VLCD with meal replacement is effective for achieving diabetes remission in individuals with obesity lasting for at least 2 years. ${ }^{18,19}$ Another form of the VLCD - the verylow-calorie ketogenic diet (VLCKD) — has been proposed as a promising option for significant weight loss in a short duration of time and stability for 2 years. ${ }^{20}$ The VLCKD consists of very-low-calorie ( $<700-800 \mathrm{kcal} /$ day) and low-carbohydrate ( $<30-50 \mathrm{~g} /$ day) intake along with adequate protein consumption (equivalent to 0.8 $1.2 \mathrm{~g} /$ day $/ \mathrm{kg}$ of ideal body weight) for a short period, followed by a gradual switch to a low-calorie diet. The VLCKD program is recommended by the Italian Society of Endocrinology in cases of severe obesity, sarcopenic obesity, obesity associated with T2DM, hypertriglyceridemia, and hypertension. ${ }^{21}$ However, this program is contraindicated in pregnant women; those with type 1 diabetes mellitus (T1DM), kidney failure, or cardiac arrhythmia; and older patients with frailty.

\section{Meal replacements}

Meal replacements include not only products marketed as soups, shakes, and bars, but also portion-controlled, ready-made meals. Meal replacements are used instead of "normal" food for one or more meals to reduce the daily calorie intake. Meal replacements can be useful for calorie control because people tend to overestimate or underestimate the amount of calories in food. ${ }^{22}$ A systematic review showed the usefulness of meal replacement in weight loss, demonstrating a mean difference of -2.22 to $-6.13 \mathrm{~kg}$ compared with other diets involving support alone. ${ }^{23}$ Despite their convenience and affordability, meal replacements are typically not successful for maintaining weight loss over a long duration.

In summary, evidence shows that an energy deficit is the most important factor for weight loss, but metabolic adaptations to decrease energy intake can also lead to reduced energy expenditure. Therefore, long-term strategies for inducing an energy deficit are 
needed. If traditional low-calorie diet programs do not work or when there is a need for significant weight loss, a VLCD and meal replacement diets can be useful options.

\section{TYPES OF FOOD EATEN}

\section{Low-fat diet}

The strategy of reducing total fat intake is widely used for weight loss because a single gram of fat contains more calories than a gram of carbohydrates or protein. A low-fat diet usually consists of a dietary composition of fat ranging from very low $(\leq 10 \%$ of calories from fat) to more moderate ( $\leq 30 \%$ of calories from fat and $<7 \%$ $10 \%$ from saturated fatty acids) ${ }^{24}$ However, randomized trials have failed to demonstrate better weight-loss maintenance by reducing energy intake from fat than other dietary interventions. ${ }^{25}$ The results of a meta-analysis did not support use of low-fat diets over other dietary interventions for long-term weight loss. ${ }^{26}$

In another study, although low-density lipoprotein cholesterol (LDL-C) level was reduced among individuals with obesity who followed a low-fat diet, triglyceride level increased and high-density lipoprotein cholesterol levels decreased. ${ }^{27}$ Another review revealed that diets high in fat and saturated fatty acids could have unfavorable effects on the gut microbiota and are associated with an unhealthy metabolic state. ${ }^{28}$ Consuming large amounts of energydense foods with a high saturated fatty acid content can cause dysbiosis in the gut and is associated with obesity and low-grade chronic inflammation. ${ }^{29}$ Thus, diets low in saturated fatty acids, as well as those supplemented with good-quality fat and fibers, are a reliable and healthy strategy for people with obesity to achieve weight management and to prevent some types of cancer (including colorectal cancer and breast cancer) ${ }^{30,31}$ when combined with total calorie restriction.

\section{Low-carbohydrate diet}

Although an energy deficit is the most important way to lose weight, weight regain after successful weight loss is very common and may seem inevitable. Thus, alternative dietary approaches for weight loss and its maintenance have become an area of interest among researchers and healthcare professionals.

Low-carbohydrate (low-carb) diets have been widely used not only for weight reduction, but also to manage T2DM; many randomized controlled trials have been conducted. ${ }^{32,33} \mathrm{~A}$ low-carb diet is defined as a carbohydrate intake below the lower boundary of the macronutrient distribution range for healthy adults (45\%-65\% of total daily energy) $)^{34}$ and encompasses a range of carbohydrate intake from $50-130 \mathrm{~g} /$ day or $10 \%-45 \%$ total energy from carbohydrates. $^{35,36}$ With carbohydrate intake $<10 \%$ (or $<20-50 \mathrm{~g} /$ day), nutritional ketosis can occur; this type of diet is called a ketogenic diet. In this situation, daily protein intake is usually $0.8-1.5 \mathrm{~g} / \mathrm{kg}$ of ideal body weight to preserve lean body mass. ${ }^{37}$

A systematic review and network meta-analysis that compared 14 dietary macronutrient patterns showed that most macronutrient diets resulted in modest weight loss over 6 months, but weight reduction and improvements in cardiometabolic factors largely disappeared after 12 months. ${ }^{38} \mathrm{~A}$ review of macronutrient patternbased diets without specific calorie targets suggested that the Atkins diet, which involves low carbohydrate intake and high protein intake, was effective for clinically meaningful weight loss at 6 and 12 months post-initiation. ${ }^{7}$ Moreover, a recent review showed that the Mediterranean diet provided the strongest and most consistent benefits for both weight loss and improvement in cardiometabolic parameters. ${ }^{39}$ It should be noted that adequate protein intake is extremely important in calorie restriction for preservation of muscle mass ${ }^{40}$ regardless of diet.

\section{Ketogenic diet}

Ketogenic diet is characterized by an extreme reduction in carbohydrate intake ( $<50 \mathrm{~g} /$ day $)$ and a relative increase in the proportions of protein and fat. ${ }^{41}$ Ketogenic diets may decrease appetite and increase lipolysis, which may result in greater metabolic efficiency for fat consumption and can provide the same thermic effects as proteins. ${ }^{41}$ There are several types of carbohydrate-restricted diets, some of which limit carbohydrates to certain levels without restricting dietary protein and fat (such as the Atkins diet), whereas others allow moderate carbohydrate intake as well as moderate protein and fat intake. ${ }^{37}$

In one study, ketogenic diet showed mixed effects on LDL-C level and was not superior to other dietary interventions for weight loss. ${ }^{37}$ Ketogenic diet can suppress hunger during calorie restriction and may have some therapeutic effects on T2DM, polycystic ovary 
syndrome, and cardiovascular and neurological diseases. However, more evidence is required to confirm its effectiveness and safety. ${ }^{37,41,42}$ Similar to VLCKDs, ketogenic diet is contraindicated in pregnant women; those with T1DM, kidney failure, or cardiac arrhythmia; and in older patients with frailty.

\section{High-protein diet}

High-protein diet has been popularized as a promising tool for weight loss because it improves satiety and decreases fat mass. ${ }^{43} \mathrm{Di}$ etary guidelines for adults recommend protein intake of $46-56 \mathrm{~g}$ or $0.8 \mathrm{~g} / \mathrm{kg}$ of ideal body weight per day. ${ }^{44}$ Thus, if dietary protein consumption exceeds $0.8 \mathrm{~g} / \mathrm{kg} / \mathrm{day}$, it is considered a high-protein diet. Usually, a high-protein diet refers to an increased protein intake to $30 \%$ of the total daily calories or $1-1.2 \mathrm{~g} / \mathrm{kg}$ of the ideal body weight per day. The Atkins diet has gained popularity as a non-energy-restricting, low-carbohydrate, high-protein, and highfat diet. ${ }^{45}$ In addition, diets high in protein with normal amounts of carbohydrates have been used to improve metabolic parameters. ${ }^{46}$ Diets with higher protein intake can provide significant benefits to prevent weight regain. ${ }^{47}$ A satiating effect is most significant with high-protein diets, and this effect helps decrease energy intake and maintain successful weight loss.

The thermic effect of food, which is called diet-induced thermogenesis, is increased energy expenditure that results from nutrient processing; these values are highest for protein. ${ }^{48}$ Secretion of gut neuropeptides that induce satiation, such as glucagon-like peptide-1 or cholecystokinin, is increased in high-protein diets. ${ }^{49}$ These types of diets also may help preserve lean body mass during weight loss. ${ }^{50}$ A meta-analysis showed that protein supplementation can help preserve lean body mass in adults and older adults, although the effects on muscle strength and synthesis were less clear. ${ }^{51}$

Some studies have indicated that high intakes of protein and fat can increase the risk of T2DM. ${ }^{52}$ In addition, diets high in protein pose a potential risk to the kidneys due to their associated proteininduced acid loads, such as the sulfuric acid produced from oxidation of methionine and cysteine. ${ }^{53}$ High-protein diets do not adversely influence kidney function in healthy adults, though they are associated with increases in serum urea level and urinary calcium excretion, which might be related to a higher risk of kidney stone formation. ${ }^{54}$ Protein from red meat consumption may increase the risk of chronic kidney disease; in contrast, low-fat dairy proteins, fish, and seafood do not have such an effect; proteins from fruits and vegetables actually might be renal protective. ${ }^{55}$ Considering that obesity is associated with chronic kidney disease and a high prevalence of subclinical chronic kidney disease, ${ }^{56}$ long-term highprotein intake, especially from animal sources, should be closely monitored in patients with obesity. ${ }^{57}$

\section{Mediterranean diet}

The Mediterranean diet involves high intake of fruits and vegetables, poultry, and fish and dairy products, and little to no consumption of red meat. ${ }^{58}$ The effectiveness of the Mediterranean diet for weight loss and preventing cardiovascular disease is supported by sufficient evidence. ${ }^{59,60}$ Its benefits may extend to the reduction in cancer risk and significant reduction in digestive cancer risk. ${ }^{61} \mathrm{Ad}-$ ditionally, adherence to a Mediterranean diet may improve cognitive function and decrease the risk of dementia, although the evidence supporting this association is weak to moderate. ${ }^{62}$ One systematic review of the Mediterranean diet for long-term weight loss reported similar results to other diets despite greater weight loss than with a low-fat diet after 12 months. ${ }^{63}$ Despite this finding, a recent review reported that the Mediterranean diet showed the strongest evidence for weight loss and improvements in cardiometabolic parameters (Fig. 1). ${ }^{39}$ The Mediterranean diet is food-based, nutrient adequate, and focused on vegetables, healthy fats, and fish; thus, it is a good strategy for maintaining long-term weight reduction.

Low-fat and low-carbohydrate diets are good options for initial weight loss; in some cases, a ketogenic diet could be a viable alternative. High-protein diets may be effective in weight loss maintenance, and the Mediterranean diet not only helps with weight loss maintenance, but also aids in improving cardiovascular risk factors, cognitive functions, and mood.

\section{OTHER DIETARY STRATEGIES}

\section{Paleolithic}

The Paleolithic (Paleo) diet is also known as the hunter-gatherer diet, caveman diet, primal diet, or Stone Age diet; all these diets suggest that our bodies have not evolved to handle highly processed foods. ${ }^{64}$ This diet follows the nutritional patterns of early humans 


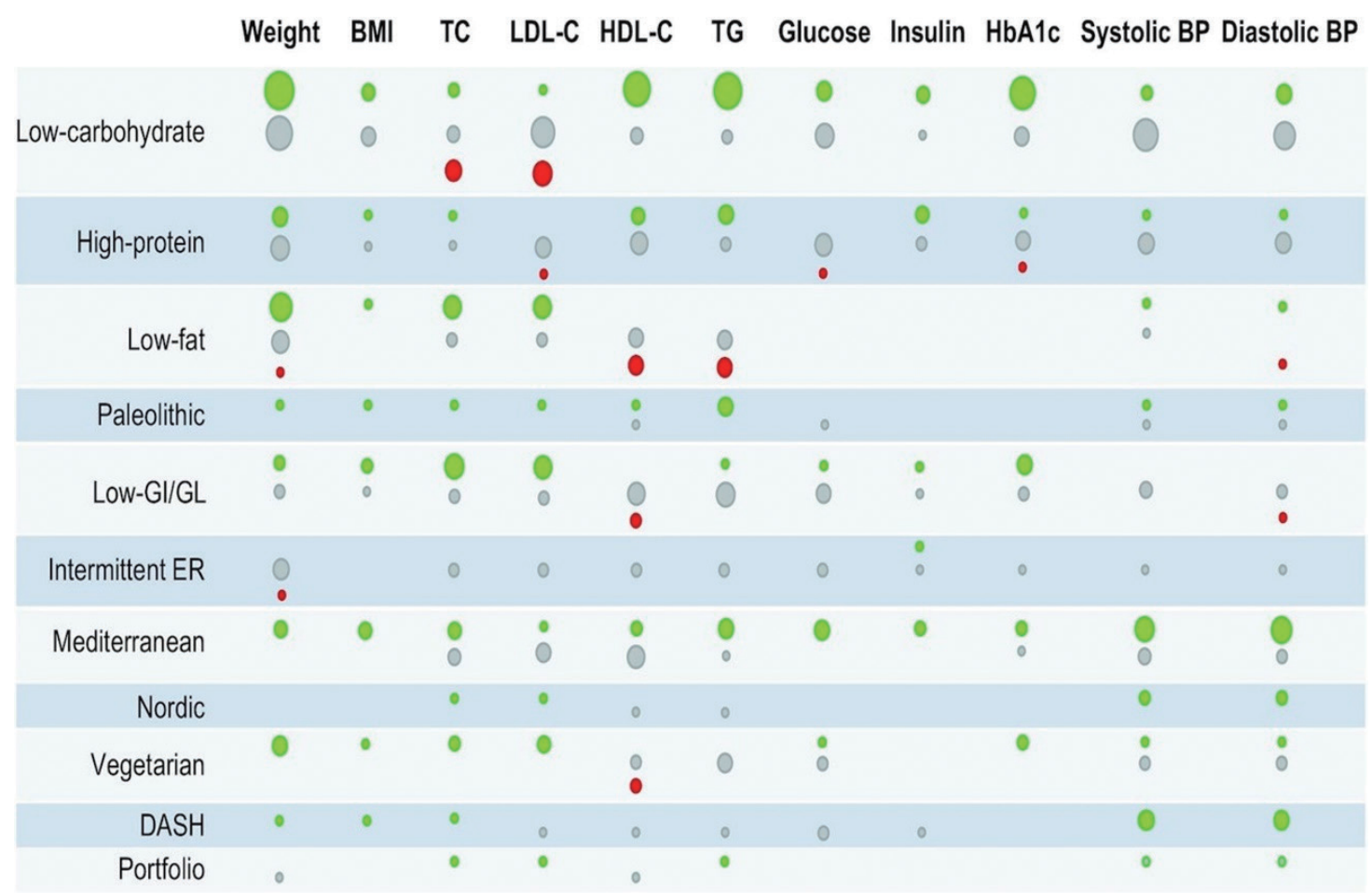

Figure 1. Summary of the results reported by a meta-analysis of randomized controlled trials in adults according to dietary interventions. Green: evidence of a beneficial effect (i.e., a decrease in all outcomes except HDL-C); grey: no effect; red: evidence of a detrimental effect (i.e., an increase in all outcomes except HDL-C). The size of the circles reflects the number of unique meta-analyses available. BMI, body mass index; TC, total cholesterol; LDL-C, low-density lipoprotein cholesterol; HDL-C, high-density lipoprotein cholesterol; TG, triglycerides; HbA1c, glycated hemoglobin; BP, blood pressure; Gl, glycemic index; GL, glycemic load; ER, energy restriction; DASH, Dietary Approaches to Stop Hypertension. Adapted from Dinu M, et al. Adv Nutr 2020;11:815-33, with permission from Elsevier. ${ }^{39}$

who lived in the Paleolithic era, which began more than 2 million years ago and continued until about 10,000 years ago, when humans started to cultivate plants and domesticate animals. Estimates are that our ancestors took in $35 \%$ of their calories from fat, $35 \%$ as carbohydrates (mostly fruits and vegetables), and $30 \%$ from protein. ${ }^{65}$ This diet advises consuming lean meat, fish, vegetables, fruits, and nuts while avoiding grains, dairy products, processed foods, and added sugar and salt. A review regarding the Paleo diet and its impact on cardiovascular risk factors suggested that it has favorable effects on lipid profile, blood pressure, and circulating C-reactive protein concentrations, but the evidence is not yet conclusive. ${ }^{66}$ The Paleo diet emphasizes vegetables and unprocessed foods, but it is also high in saturated fats, which might increase the risk of cardiovascular disease.

\section{Low glycemic index/glycemic load diet}

The glycemic index (GI) is a measurement system that ranks foods according to effect on blood glucose level; the rates at which different foods raise blood glucose level are ranked in comparison with absorption of $50 \mathrm{~g}$ of pure glucose as a reference $(\mathrm{GI}=100){ }^{67}$ A low-GI diet emphasizes exchanging high-GI foods for low-GI alternatives. Nothing is strictly forbidden with the low-GI diet, but high-GI foods such as white bread, bagels, cereals, mashed potatoes, pasta, and noodles should be replaced by low-GI foods. The low-GI diet offers benefits in managing T2DM and decreasing body weight. ${ }^{68}$ However, one study found no differences in weight among low-GI diets and a diet based on healthy nutritional recommendations among overweight adolescent girls. ${ }^{69}$ The low-GI diet also does not provide a complete nutritional picture and does not include recommendations for daily intake of fat, protein, or fiber.

\section{Nordic diet}

The new Nordic diet is based on unprocessed whole grains, high-fiber vegetables, fish, low-fat dairy foods, lean meat of all types (beef, pork, lamb), beans and lentils, fruit, dense breads, tofu, and skinless poultry. ${ }^{70}$ This diet recommends more calories from plant 
foods and fewer from meat and more foods from the sea, lakes, and the wild countryside. It is based on whole and minimally processed foods and is high in both fiber and omega-3 fats. A systemic review showed that adherence to the Nordic diet significantly improved body weight. ${ }^{71}$ However, these types of food may be not easily accessible or affordable for everyone and may make the diet difficult to maintain.

\section{Vegetarian diet}

There are many reasons to adopt a vegetarian diet for health. These diets can lower the risk of ischemic heart disease, T2DM, and cancer. ${ }^{72}$ Vegetarian diets can reduce blood pressure, ${ }^{73}$ lipid profiles, ${ }^{74}$ and inflammatory biomarkers ${ }^{75}$ and improve glycemic control ${ }^{76}$ and other cardiometabolic risk factors. ${ }^{77}$ This diet excludes meat, fish, and poultry, but there are many variations of the diet, including lactovegetarians and lacto-ovo-vegetarians. Dietary guidelines recommend vegetarian-patterned diets. ${ }^{78} \mathrm{~A}$ systemic review suggested that vegetarian diets reduce mean body weight, but the studies are few and of variable quality. ${ }^{79}$ Since fish and seafood are excluded, this diet is low in omega-3 fats.

\section{Dietary approaches to stop hypertension}

The Dietary Approaches to Stop Hypertension (DASH) diet was originally developed to lower blood pressure without medication, but it is now considered one of the healthiest eating patterns. ${ }^{80}$ The DASH plan includes many vegetables, fruits, and grains with an emphasis on whole grains. Low-fat or non-fat dairy foods, pulses, nuts, seeds, lean meats, poultry, and seafood are also allowed. The diet limits sodium intake to $2,300 \mathrm{mg} /$ day and can reduce the risk of cancer, ${ }^{81}$ cardiovascular risk factors, ${ }^{82}$ and both all-cause and causespecific mortality. ${ }^{83}$ The DASH diet also aids in losing weight, but the differences were relatively small. ${ }^{84}$

\section{Portfolio}

The Portfolio diet is a vegan plan that emphasizes a "portfolio" of foods or food components that lower cholesterol. ${ }^{85}$ When these foods are eaten together as part of a healthy diet, they presumably lower LDL-C better than any one of the portfolio foods could alone. To include a portfolio of cholesterol-lowering foods, the diet recommends daily consumption of $2 \mathrm{~g}$ of plant sterols, $50 \mathrm{~g}$ of nuts,
10-25 $\mathrm{g}$ of soluble fibers from plant foods, and $50 \mathrm{~g}$ of soy protein; meat, poultry, seafood, dairy, and eggs are not allowed. This diet also helps reduce LDL-C, ${ }^{86}$ but its effects on weight loss were small $(-0.8 \mathrm{~kg}$ to $-1.2 \mathrm{~kg}){ }^{87}$

\section{TIMING OF MEAL CONSUMPTION}

\section{Intermittent fasting}

Recently, fasting has received interest not only from medical experts, but also from members of the general public with an interest in health. Intermittent fasting involves regular periods with no or very limited calorie intake. The three most widely used regimens are alternate-day fasting, 5:2 intermittent fasting (fasting or consuming 900-1,000 calories for 2 days each week), and daily timerestricted feeding (fasting for 16-18 hours a day). ${ }^{88}$ The benefits of intermittent fasting come not only from reduction in calorie intake, but also from its effects on metabolic switching to reverse insulin resistance, strengthen the immune system, and enhance physical and cognitive functions. ${ }^{88}$ Recent reviews on intermittent fasting have suggested that, as a weight-loss strategy, it could benefit patients with obesity and has effects comparable to daily calorie restriction. ${ }^{89}$ However, little is known about the long-term sustainability and health effects of this type of fasting.

Intermittent fasting focuses on the time window of eating instead of calorie calculations or macronutrient composition, helping people to restrict food intake without having to count calories and to avoid late-night snacking. With this diet, careful attention should be paid to patients being treated with hypoglycemic agents because fasting might cause dizziness, general weakness, halitosis, headache, chills, and lack of concentration, although no serious adverse events have been reported. ${ }^{89}$

\section{Meal timing}

Recently, much interest has focused on "when to eat." Meal timing and the circadian rhythm have raised a novel issue in weight management. ${ }^{90}$ Alterations in circadian rhythms produce biochemical, physiological, and behavioral circadian rhythm disruptions, which can be caused by the lack of change between day/night synchronization (such as being exposed to artificial light at night), eating at night, or a shift in time due to jet lag or shift work..$^{90}$ Eating 
late can cause circadian disruption, resulting in production of free cortisol, changes in daily rhythms of body temperature, decreased resting energy expenditure, and decreased glucose tolerance. ${ }^{91,92}$ Thus, timing of meals could have serious implications not only for weight management, but also for development of cardiovascular disease. A recent review confirmed that skipping breakfast increased the risk of overweight and obesity. ${ }^{93}$ Additionally, latenight eating was associated with obesity as well as metabolic syndrome. $^{94}$

The American Heart Association recommends distributing calories over a defined period of the day, consuming a greater share of the total calorie intake earlier in the day, and maintaining consistent overnight fasting periods. ${ }^{95}$ Eating a high-calorie breakfast and overnight fasting could have positive effects on prevention of obesity, while intermittent fasting may help control calorie intake in people with obesity.

\section{CONCLUSION}

There is no single best strategy for weight management, although some evidence-based methods have been suggested (Table 1). Reducing daily calorie intake is the most important factor for weight loss. Low-calorie recipes, especially those for low-fat or low-carbohydrate diets, have been suggested as the first dietary strategy, although in some cases, a VLCD is required for a short period. Except for energy deficit, there seems to be no significant difference between macronutrient composition-based diets. Improvement in cardiometabolic factors strongly depends on degree of weight loss. However, as in the Mediterranean diet, increasing consumption of fruits and vegetables and intake of healthy fats (including monounsaturated as well as polyunsaturated fats) can be a healthy strategy for weight loss and maintenance. Additionally, increased protein intake can help with weight loss maintenance.

Eating breakfast and avoiding late-night eating should be consid-

Table 1. Dietary strategies for weight loss

\begin{tabular}{|c|c|}
\hline Type & Brief description \\
\hline \multicolumn{2}{|l|}{ Amount of food intake } \\
\hline Low-calorie diet & $\begin{array}{l}\text { Consumption of 1,000-1,500 calories and deficit of 500-750 calories per day }{ }^{12-15} \\
\text { Recommended as the initial strategy }\end{array}$ \\
\hline Very-low-calorie diet & $\begin{array}{l}\text { Consumption of } 600-900 \text { calories per day } \\
\text { Can be maintained for a relatively short time period of time ( } 2 \text { weeks to } 3 \text { months), followed by a gradual switch to a low-calorie diet }{ }^{18,19} \\
\text { Considered for severe obesity, sarcopenic obesity, obesity associated with type } 2 \text { diabetes, hypertriglyceridemia, and hypertension }{ }^{21}\end{array}$ \\
\hline Meal replacements & $\begin{array}{l}\text { Useful for controlling calories without placing much effort on calorie calculation or meal planning } \\
\text { May include either total or partial meal replacements (one or two meals a day) }\end{array}$ \\
\hline \multicolumn{2}{|l|}{ Type of food eaten } \\
\hline Low-fat diet & $\begin{array}{l}\text { Consumption of fat as }<15 \%-20 \% \text { of daily calories, especially saturated fatty acids as }<7 \%-10 \%^{24} \\
\text { Mostly plant-based meals }\end{array}$ \\
\hline Low-carbohydrate diet & $\begin{array}{l}\text { Consumption of carbohydrates as }<45 \% \text { of daily calories or }<130 \mathrm{mg} / \text { day }^{32-34} \\
\text { Recommended as a dietary strategy for type } 2 \text { diabetes }{ }^{32,33} \\
\text { Might be useful for initial weight loss, but long-term results are similar to following a low-fat diet }{ }^{38}\end{array}$ \\
\hline Ketogenic diet & $\begin{array}{l}\text { Consumption of carbohydrates as }<10 \% \text { of daily calories or }<50 \mathrm{mg} / \text { day }^{41} \\
\text { May decrease appetite, but long-term safety is unknown }\end{array}$ \\
\hline High-protein diet & $\begin{array}{l}\text { Increase protein intake to } 30 \% \text { of total daily calories or } 1-1.2 \mathrm{~g} / \mathrm{kg} \text { of ideal body weight }{ }^{43} \\
\text { Useful in maintaining weight loss and increasing satiety }{ }^{47} \\
\text { High-protein diets from animal sources should be handled with caution for people with risk of chronic kidney disease. }{ }^{57}\end{array}$ \\
\hline Mediterranean diet & $\begin{array}{l}\text { Consists of high consumption of fruits and vegetables, poultry, fish, dairy products, and monounsaturated fats, with little to no consumption of red } \\
\text { meat }{ }^{58} \\
\text { Helpful in improving cardiometabolic parameters and cognitive function }{ }^{59,60}\end{array}$ \\
\hline \multicolumn{2}{|c|}{ Timing of meal consumption } \\
\hline Intermittent fasting ${ }^{88}$ & $\begin{array}{l}\text { Alternate day fasting } \\
\text { 5:2 Intermittent fasting (fasting or consuming }<1,000 \text { calories for } 2 \text { days each week) } \\
\text { Daily time-restricted feeding (fasting for 16-18 hours a day) } \\
\text { Effective as a weight-loss strategy } \\
\text { Attention should be paid to patients currently being treated with hypoglycemic agents }{ }^{89}\end{array}$ \\
\hline Meal timing & Consume a higher calorie breakfast and comply with overnight fasting to prevent obesity \\
\hline
\end{tabular}


ered important dietary strategies not only for weight loss, but also for metabolic health and are based on the physiologic clock. Timerestricted eating or intermittent fasting can be considered other options for weight loss and its maintenance. Maintenance of a lowcalorie intake should be continued throughout an individual's lifespan. Thus, the best diet for weight management is one that can be maintained in the long term. Healthcare providers should consult with patients before choosing the optimal diet strategy because successful weight loss and its maintenance depend on the patient's choices, preferences, and long-term adherence to the diet plan.

\section{CONFLICTS OF INTEREST}

$\mathrm{Ju}$ Young Kim is the Editorial Board member of the Journal of Obesity \& Metabolic Syndrome. However, she is not involved in the peer reviewer selection, evaluation, or decision process of this article. Otherwise, no other potential conflicts of interest relevant to this article were reported.

\section{REFERENCES}

1. World Health Organization. Controlling the global obesity epidemic. Geneva: World Health Organization; 2020.

2. Egger G, Dixon J. Beyond obesity and lifestyle: a review of 21st century chronic disease determinants. Biomed Res Int 2014;2014:731685.

3. Smith CJ, Perfetti TA, Hayes AW, Berry SC. Obesity as a source of endogenous compounds associated with chronic disease: a review. Toxicol Sci 2020;175:149-55.

4. Makris A, Foster GD. Dietary approaches to the treatment of obesity. Psychiatr Clin North Am 2011;34:813-27.

5. Volek JS, Vanheest JL, Forsythe CE. Diet and exercise for weight loss: a review of current issues. Sports Med 2005;35:1-9.

6. Johnston BC, Kanters S, Bandayrel K, Wu P, Naji F, Siemieniuk RA, et al. Comparison of weight loss among named diet programs in overweight and obese adults: a meta-analysis. JAMA 2014;312:923-33.

7. Anton SD, Hida A, Heekin K, Sowalsky K, Karabetian C, Mutchie $\mathrm{H}$, et al. Effects of popular diets without specific calorie targets on weight loss outcomes: systematic review of findings from clinical trials. Nutrients 2017;9:822.

8. Atallah R, Filion KB, Wakil SM, Genest J, Joseph L, Poirier P, et al. Long-term effects of 4 popular diets on weight loss and cardiovascular risk factors: a systematic review of randomized controlled trials. Circ Cardiovasc Qual Outcomes 2014;7: 815-27.

9. Cho Y, Hong N, Kim KW, Cho SJ, Lee M, Lee YH, et al. The effectiveness of intermittent fasting to reduce body mass index and glucose metabolism: a systematic review and meta-analysis. J Clin Med 2019;8:1645.

10. Mendenhall E, Singer M. The global syndemic of obesity, undernutrition, and climate change. Lancet 2019;393:741.

11. Hall KD, Guo J. Obesity energetics: body weight regulation and the effects of diet composition. Gastroenterology 2017; 152:1718-27.

12. Seo MH, Lee WY, Kim SS, Kang JH, Kang JH, Kim KK, et al. 2018 Korean society for the study of obesity guideline for the management of obesity in Korea. J Obes Metab Syndr 2019; 28:40-5.

13. Yi DY, Kim SC, Lee JH, Lee EH, Kim JY, Kim YJ, et al. Clinical practice guideline for the diagnosis and treatment of pediatric obesity: recommendations from the Committee on Pediatric Obesity of the Korean Society of Pediatric Gastroenterology Hepatology and Nutrition. Korean J Pediatr 2019;62: 3-21.

14. Ryan DH, Kahan S. Guideline recommendations for obesity management. Med Clin North Am 2018;102:49-63.

15. Turner LR, Harris MF, Mazza D. Obesity management in general practice: does current practice match guideline recommendations? Med J Aust 2015;202:370-2.

16. Gardner CD, Trepanowski JF, Del Gobbo LC, Hauser ME, Rigdon J, Ioannidis JP, et al. Effect of low-fat vs low-carbohydrate diet on 12-month weight loss in overweight adults and the association with genotype pattern or insulin secretion: the DIETFITS randomized clinical trial. JAMA 2018;319: 667-79.

17. Parretti HM, Jebb SA, Johns DJ, Lewis AL, Christian-Brown AM, Aveyard P. Clinical effectiveness of very-low-energy diets in the management of weight loss: a systematic review and meta-analysis of randomized controlled trials. Obes Rev 2016; 
$17: 225-34$

18. Lean ME, Leslie WS, Barnes AC, Brosnahan N, Thom G, McCombie L, et al. Primary care-led weight management for remission of type 2 diabetes (DiRECT): an open-label, cluster-randomised trial. Lancet 2018;391:541-51.

19. Lean ME, Leslie WS, Barnes AC, Brosnahan N, Thom G, McCombie L, et al. Durability of a primary care-led weightmanagement intervention for remission of type 2 diabetes: 2-year results of the DiRECT open-label, cluster-randomised trial. Lancet Diabetes Endocrinol 2019;7:344-55.

20. Chang JJ, Bena J, Kannan S, Kim J, Burguera B, Kashyap SR. Limited carbohydrate refeeding instruction for long-term weight maintenance following a ketogenic, very-low-calorie meal plan. Endocr Pract 2017;23:649-56.

21. Caprio M, Infante M, Moriconi E, Armani A, Fabbri A, Mantovani G, et al. Very-low-calorie ketogenic diet (VLCKD) in the management of metabolic diseases: systematic review and consensus statement from the Italian Society of Endocrinology (SIE). J Endocrinol Invest 2019;42:1365-86.

22. Brown RE, Canning KL, Fung M, Jiandani D, Riddell MC, Macpherson AK, et al. Calorie estimation in adults differing in body weight class and weight loss status. Med Sci Sports Exerc 2016;48:521-6.

23. Astbury NM, Piernas C, Hartmann-Boyce J, Lapworth S, Aveyard P, Jebb SA. A systematic review and meta-analysis of the effectiveness of meal replacements for weight loss. Obes Rev 2019;20:569-87.

24. Liu AG, Ford NA, Hu FB, Zelman KM, Mozaffarian D, KrisEtherton PM. A healthy approach to dietary fats: understanding the science and taking action to reduce consumer confusion. Nutr J 2017;16:53.

25. McManus K, Antinoro L, Sacks F. A randomized controlled trial of a moderate-fat, low-energy diet compared with a low fat, low-energy diet for weight loss in overweight adults. Int $\mathrm{J}$ Obes Relat Metab Disord 2001;25:1503-11.

26. Tobias DK, Chen M, Manson JE, Ludwig DS, Willett W, Hu FB. Effect of low-fat diet interventions versus other diet interventions on long-term weight change in adults: a systematic review and meta-analysis. Lancet Diabetes Endocrinol 2015;3: 968-79.
27. Lu M, Wan Y, Yang B, Huggins CE, Li D. Effects of low-fat compared with high-fat diet on cardiometabolic indicators in people with overweight and obesity without overt metabolic disturbance: a systematic review and meta-analysis of randomised controlled trials. Br J Nutr 2018;119:96-108.

28. Wolters M, Ahrens J, Romaní-Pérez M, Watkins C, Sanz Y, Benítez-Páez A, et al. Dietary fat, the gut microbiota, and metabolic health: a systematic review conducted within the MyNewGut project. Clin Nutr 2019;38:2504-20.

29. Redondo-Useros N, Nova E, González-Zancada N, Díaz LE, Gómez-Martínez S, Marcos A. Microbiota and lifestyle: a special focus on diet. Nutrients 2020;12:1776.

30. Ocvirk S, Wilson AS, Appolonia CN, Thomas TK, O’Keefe SJ. Fiber, fat, and colorectal cancer: new insight into modifiable dietary risk factors. Curr Gastroenterol Rep 2019;21:62.

31. Brennan SF, Woodside JV, Lunny PM, Cardwell CR, Cantwell MM. Dietary fat and breast cancer mortality: a systematic review and meta-analysis. Crit Rev Food Sci Nutr 2017;57:19992008.

32. van Zuuren EJ, Fedorowicz Z, Kuijpers T, Pijl H. Effects of low-carbohydrate- compared with low-fat-diet interventions on metabolic control in people with type 2 diabetes: a systematic review including GRADE assessments. Am J Clin Nutr 2018;108:300-31.

33. Kelly T, Unwin D, Finucane F. Low-carbohydrate diets in the management of obesity and type 2 diabetes: a review from clinicians using the approach in practice. Int J Environ Res Public Health 2020;17:2557.

34. Dietary Guidelines Advisory Committee. Scientific report of the 2015 Dietary Guidelines Advisory Committee: advisory report to the secretary of health and human services and the secretary of agriculture. Washington (DC): U.S. Department of Agriculture; 2015.

35. Mansoor N, Vinknes KJ, Veierød MB, Retterstøl K. Effects of low-carbohydrate diets v. low-fat diets on body weight and cardiovascular risk factors: a meta-analysis of randomised controlled trials. Br J Nutr 2016;115:466-79.

36. Sackner-Bernstein J, Kanter D, Kaul S. Dietary intervention for overweight and obese adults: comparison of low-carbohydrate and low-fat diets: a meta-analysis. PLoS One 2015;10: 
e0139817.

37. Kirkpatrick CF, Bolick JP, Kris-Etherton PM, Sikand G, Aspry $\mathrm{KE}$, Soffer DE, et al. Review of current evidence and clinical recommendations on the effects of low-carbohydrate and verylow-carbohydrate (including ketogenic) diets for the management of body weight and other cardiometabolic risk factors: a scientific statement from the National Lipid Association Nutrition and Lifestyle Task Force. J Clin Lipidol 2019;13: 689-711.

38. Ge L, Sadeghirad B, Ball GD, da Costa BR, Hitchcock CL, Svendrovski A, et al. Comparison of dietary macronutrient patterns of 14 popular named dietary programmes for weight and cardiovascular risk factor reduction in adults: systematic review and network meta-analysis of randomised trials. BMJ 2020;369:m696.

39. Dinu M, Pagliai G, Angelino D, Rosi A, Dall'Asta M, Bresciani L, et al. Effects of popular diets on anthropometric and cardiometabolic parameters: an umbrella review of meta-analyses of randomized controlled trials. Adv Nutr 2020;11:815-33.

40. Rondanelli M, Faliva MA, Gasparri C, Peroni G, Spadaccini D, Maugeri R, et al. Current opinion on dietary advice in order to preserve fat-free mass during a low-calorie diet. Nutrition 2020;72:110667.

41. Paoli A, Rubini A, Volek JS, Grimaldi KA. Beyond weight loss: a review of the therapeutic uses of very-low-carbohydrate (ketogenic) diets. Eur J Clin Nutr 2013;67:789-96.

42. Gibson AA, Seimon RV, Lee CM, Ayre J, Franklin J, Markovic TP, et al. Do ketogenic diets really suppress appetite? A systematic review and meta-analysis. Obes Rev 2015;16:64-76.

43. Halton TL, Hu FB. The effects of high protein diets on thermogenesis, satiety and weight loss: a critical review. J Am Coll Nutr 2004;23:373-85.

44. Berryman CE, Lieberman HR, Fulgoni VL 3rd, Pasiakos SM. Protein intake trends and conformity with the dietary reference intakes in the United States: analysis of the National Health and Nutrition Examination Survey, 2001-2014. Am J Clin Nutr 2018;108:405-13.

45. Nagy R. Dr. Atkins' diet revolution: a review. Va Med Mon (1918) 1974;101:383-5.

46. St Jeor ST, Howard BV, Prewitt TE, Bovee V, Bazzarre T, Eck- el $\mathrm{RH}$, et al. Dietary protein and weight reduction: a statement for healthcare professionals from the Nutrition Committee of the Council on Nutrition, Physical Activity, and Metabolism of the American Heart Association. Circulation 2001;104: 1869-74.

47. van Baak MA, Mariman EC. Dietary strategies for weight loss maintenance. Nutrients 2019;11:1916.

48. Westerterp KR. Diet induced thermogenesis. Nutr Metab (Lond) 2004;1:5.

49. Lejeune MP, Westerterp KR, Adam TC, Luscombe-Marsh ND, Westerterp-Plantenga MS. Ghrelin and glucagon-like peptide 1 concentrations, 24-h satiety, and energy and substrate metabolism during a high-protein diet and measured in a respiration chamber. Am J Clin Nutr 2006;83:89-94.

50. Pasiakos SM, Cao JJ, Margolis LM, Sauter ER, Whigham LD, McClung JP, et al. Effects of high-protein diets on fat-free mass and muscle protein synthesis following weight loss: a randomized controlled trial. FASEB J 2013;27:3837-47.

51. Wirth J, Hillesheim E, Brennan L. The role of protein intake and its timing on body composition and muscle function in healthy adults: a systematic review and meta-analysis of randomized controlled trials. J Nutr 2020;150:1443-60.

52. Shan R, Duan W, Liu L, Qi J, Gao J, Zhang Y, et al. Low-carbohydrate, high-protein, high-fat diets rich in livestock, poultry and their products predict impending risk of type 2 diabetes in Chinese individuals that exceed their calculated caloric requirement. Nutrients 2018;10:77.

53. Reddy ST, Wang CY, Sakhaee K, Brinkley L, Pak CY. Effect of low-carbohydrate high-protein diets on acid-base balance, stone-forming propensity, and calcium metabolism. Am J Kidney Dis 2002;40:265-74.

54. Schwingshackl L, Hoffmann G. Comparison of high vs. nor$\mathrm{mal} /$ low protein diets on renal function in subjects without chronic kidney disease: a systematic review and meta-analysis. PLoS One 2014;9:e97656.

55. Haring B, Selvin E, Liang M, Coresh J, Grams ME, PetruskiIvleva $\mathrm{N}$, et al. Dietary protein sources and risk for incident chronic kidney disease: results from the atherosclerosis risk in communities (ARIC) study. J Ren Nutr 2017;27:233-42.

56. Garofalo C, Borrelli S, Minutolo R, Chiodini P, De Nicola L, 
Conte G. A systematic review and meta-analysis suggests obesity predicts onset of chronic kidney disease in the general population. Kidney Int 2017;91:1224-35.

57. Ko GJ, Rhee CM, Kalantar-Zadeh K, Joshi S. The effects of high-protein diets on kidney health and longevity. J Am Soc Nephrol 2020;31:1667-79.

58. Shai I, Schwarzfuchs D, Henkin Y, Shahar DR, Witkow S, Greenberg I, et al. Weight loss with a low-carbohydrate, Mediterranean, or low-fat diet. N Engl J Med 2008;359:229-41.

59. Sánchez-Sánchez ML, García-Vigara A, Hidalgo-Mora JJ, García-Pérez MÁ, Tarín J, Cano A. Mediterranean diet and health: a systematic review of epidemiological studies and intervention trials. Maturitas 2020;136:25-37.

60. Liyanage T, Ninomiya T, Wang A, Neal B, Jun M, Wong MG, et al. Effects of the Mediterranean diet on cardiovascular outcomes-a systematic review and meta-analysis. PLoS One 2016; 11:e0159252.

61. Barak Y, Fridman D. Impact of Mediterranean diet on cancer: focused literature review. Cancer Genomics Proteomics 2017; 14:403-8.

62. Petersson SD, Philippou E. Mediterranean diet, cognitive function, and dementia: a systematic review of the evidence. Adv Nutr 2016;7:889-904.

63. Mancini JG, Filion KB, Atallah R, Eisenberg MJ. Systematic review of the Mediterranean diet for long-term weight loss. Am J Med 2016;129:407-15.

64. Challa HJ, Bandlamudi M, Uppaluri KR. Paleolithic diet. Treasure Island (FL): StatPearls; 2020.

65. Kuipers RS, Luxwolda MF, Dijck-Brouwer DA, Eaton SB, Crawford MA, Cordain L, et al. Estimated macronutrient and fatty acid intakes from an East African Paleolithic diet. Br J Nutr 2010;104:1666-87.

66. Ghaedi E, Mohammadi M, Mohammadi H, Ramezani-Jolfaie N, Malekzadeh J, Hosseinzadeh M, et al. Effects of a paleolithic diet on cardiovascular disease risk factors: a systematic review and meta-analysis of randomized controlled trials. Adv Nutr 2019;10:634-46.

67. Livesey G. Low-glycaemic diets and health: implications for obesity. Proc Nutr Soc 2005;64:105-13.

68. Zafar MI, Mills KE, Zheng J, Regmi A, Hu SQ, Gou L, et al.
Low-glycemic index diets as an intervention for diabetes: a systematic review and meta-analysis. Am J Clin Nutr 2019; 110:891-902.

69. Rouhani MH, Kelishadi R, Hashemipour M, Esmaillzadeh A, Azadbakht L. The effect of low glycemic index diet on body weight status and blood pressure in overweight adolescent girls: a randomized clinical trial. Nutr Res Pract 2013;7:385-92.

70. Mithril C, Dragsted LO, Meyer C, Blauert E, Holt MK, Astrup A. Guidelines for the new Nordic diet. Public Health Nutr 2012;15:1941-7.

71. Ramezani-Jolfaie N, Mohammadi M, Salehi-Abargouei A. Effects of a healthy Nordic diet on weight loss in adults: a systematic review and meta-analysis of randomized controlled clinical trials. Eat Weight Disord 2020;25:1141-50.

72. Dinu M, Abbate R, Gensini GF, Casini A, Sofi F. Vegetarian, vegan diets and multiple health outcomes: a systematic review with meta-analysis of observational studies. Crit Rev Food Sci Nutr 2017;57:3640-9.

73. Lee KW, Loh HC, Ching SM, Devaraj NK, Hoo FK. Effects of vegetarian diets on blood pressure lowering: a systematic review with meta-analysis and trial sequential analysis. Nutrients 2020;12:1604.

74. Wang F, Zheng J, Yang B, Jiang J, Fu Y, Li D. Effects of vegetarian diets on blood lipids: a systematic review and meta-analysis of randomized controlled trials. J Am Heart Assoc 2015; 4:e002408.

75. Haghighatdoost F, Bellissimo N, Totosy de Zepetnek JO, Rouhani $\mathrm{MH}$. Association of vegetarian diet with inflammatory biomarkers: a systematic review and meta-analysis of observational studies. Public Health Nutr 2017;20:2713-21.

76. Yokoyama Y, Barnard ND, Levin SM, Watanabe M. Vegetarian diets and glycemic control in diabetes: a systematic review and meta-analysis. Cardiovasc Diagn Ther 2014;4:373-82.

77. Viguiliouk E, Kendall CW, Kahleová H, Rahelić D, Salas-Salvadó J, Choo VL, et al. Effect of vegetarian dietary patterns on cardiometabolic risk factors in diabetes: a systematic review and meta-analysis of randomized controlled trials. Clin Nutr 2019;38:1133-45.

78. Melina V, Craig W, Levin S. Position of the academy of nutrition and dietetics: vegetarian diets. J Acad Nutr Diet 2016; 
116:1970-80.

79. Barnard ND, Levin SM, Yokoyama Y. A systematic review and meta-analysis of changes in body weight in clinical trials of vegetarian diets. J Acad Nutr Diet 2015;115:954-69.

80. Filippou CD, Tsioufis CP, Thomopoulos CG, Mihas CC, Dimitriadis KS, Sotiropoulou LI, et al. Dietary approaches to stop hypertension (DASH) diet and blood pressure reduction in adults with and without hypertension: a systematic review and meta-analysis of randomized controlled trials. Adv Nutr 2020;11:1150-60.

81. Ali Mohsenpour M, Fallah-Moshkani R, Ghiasvand R, Khosravi-Boroujeni $\mathrm{H}$, Mehdi Ahmadi S, Brauer $\mathrm{P}$, et al. Adherence to dietary approaches to stop hypertension (DASH)-style diet and the risk of cancer: a systematic review and meta-analysis of cohort studies. J Am Coll Nutr 2019;38:513-25.

82. Siervo M, Lara J, Chowdhury S, Ashor A, Oggioni C, Mathers JC. Effects of the Dietary Approach to Stop Hypertension (DASH) diet on cardiovascular risk factors: a systematic review and meta-analysis. Br J Nutr 2015;113:1-15.

83. Soltani S, Arablou T, Jayedi A, Salehi-Abargouei A. Adherence to the dietary approaches to stop hypertension (DASH) diet in relation to all-cause and cause-specific mortality: a systematic review and dose-response meta-analysis of prospective cohort studies. Nutr J 2020;19:37.

84. Soltani S, Shirani F, Chitsazi MJ, Salehi-Abargouei A. The effect of dietary approaches to stop hypertension (DASH) diet on weight and body composition in adults: a systematic review and meta-analysis of randomized controlled clinical trials. Obes Rev 2016;17:442-54.

85. Kendall CW, Jenkins DJ. A dietary portfolio: maximal reduction of low-density lipoprotein cholesterol with diet. Curr Atheroscler Rep 2004;6:492-8.

86. Chiavaroli L, Nishi SK, Khan TA, Braunstein CR, Glenn AJ, Mejia SB, et al. Portfolio dietary pattern and cardiovascular disease: a systematic review and meta-analysis of controlled trials. Prog Cardiovasc Dis 2018;61:43-53.

87. Jenkins DJ, Boucher BA, Ashbury FD, Sloan M, Brown P, ElSohemy A, et al. Effect of current dietary recommendations on weight loss and cardiovascular risk factors. J Am Coll Cardiol 2017;69:1103-12.

88. de Cabo R, Mattson MP. Effects of intermittent fasting on health, aging, and disease. N Engl J Med 2019;381:2541-51.

89. Welton S, Minty R, O’Driscoll T, Willms H, Poirier D, Madden $\mathrm{S}$, et al. Intermittent fasting and weight loss: systematic review. Can Fam Physician 2020;66:117-25.

90. Lopez-Minguez J, Gómez-Abellán P, Garaulet M. Circadian rhythms, food timing and obesity. Proc Nutr Soc 2016;75: 501-11.

91. Bandín C, Scheer FA, Luque AJ, Ávila-Gandía V, Zamora S, Madrid JA, et al. Meal timing affects glucose tolerance, substrate oxidation and circadian-related variables: a randomized, crossover trial. Int J Obes (Lond) 2015;39:828-33.

92. Ding G, Gong Y, Eckel-Mahan KL, Sun Z. Central circadian clock regulates energy metabolism. Adv Exp Med Biol 2018; 1090:79-103.

93. Ma X, Chen Q, Pu Y, Guo M, Jiang Z, Huang W, et al. Skipping breakfast is associated with overweight and obesity: a systematic review and meta-analysis. Obes Res Clin Pract 2020;14: 1-8.

94. Gouda M, Matsukawa M, Iijima H. Associations between eating habits and glycemic control and obesity in Japanese workers with type 2 diabetes mellitus. Diabetes Metab Syndr Obes 2018;11:647-58.

95. St-Onge MP, Ard J, Baskin ML, Chiuve SE, Johnson HM, KrisEtherton $\mathrm{P}$, et al. Meal timing and frequency: implications for cardiovascular disease prevention: a scientific statement from the American heart association. Circulation 2017;135:e96-121. 